\title{
Time Management Behaviors of Healthcare Managers and the Effects of Demographic Variables
}

\author{
Aygul Yanik, $1, *$ and Meryem Ortlek ${ }^{2}$ \\ ${ }^{1}$ Assoc. Prof. (PhD), Istanbul Medeniyet University, Istanbul, Turkey \\ ${ }^{2}$ Nurse, Corlu State Hospital, Tekirdag, Turkey \\ "Corresponding author: Aygul Yanik, Department of Health Management, Faculty of Health Management, Istanbul Medeniyet University, Istanbul, Turkey. Tel: +90-2162803150; \\ Fax:- E-mail: aygul.moon@gmail.com; aygul.yanik@medeniyet.edu.tr
}

Received 2014 November 07; Revised 2015 April 03; Accepted 2015 May 04.

\begin{abstract}
Background: Using time effectively has become increasingly important in terms of the successful performance of healthcare managers.

Objectives: In this study, the time management behaviors of healthcare managers and the effects of demographic variables on these behaviors are determined.

Methods: This cross-sectional and descriptive research was carried out on managers from five hospitals in Tekirdag, Turkey. The data was collected with the survey method. The research population of 175 managers were targeted with an initial invitation to participate in the study. However, only 163 managers accepted the invitation to complete a questionnaire. SPSS for Windows 15.0 package software was used to analyze the data.

Results: For managers, general planning, meeting management, determining priorities, substitution, table and file folder set up, procrastination, and answering unnecessary phone calls were found to occur frequently; general time management was also found to consume a significant amount of time, whereas saying "no" to visitors was determined to be of only an average level of time consumption. With respect to the scores of women, determining priorities, saying "no" to visitors, table and file folder set up, and procrastination took up more time than they did for men.
\end{abstract}

Conclusions: It was determined that demographic variables do affect the time management behaviors of healthcare managers.

Keywords: Time Management, Healthcare Managers, Hospital

\section{Background}

Time management (TM) is necessary for a productive and balanced life. By adopting effective TM principles, determining one's priorities and making good choices help an individual to improve his/her quality of life (1). Generally, TM is also considered to involve time monitoring and control (2). TM requires that a lot of work and activities be fit into a period of time which is often short. As a result, TM is defined as the management of work and other activities within a certain length of time.

From a manager's perspective, one of his/her distinctive characteristics is reliable and effective TM. In management, it is important to do more work in a certain time or to do the same amount of work in less time. In this way, productivity can be increased and more time can be spared for other interests or tasks. Successful managers are expected to manage both the clients' and service providers' time in the most effective way, as well as his/her own time. If they use their time effectively, they can contribute more to their own lives, personnels' lives, clients' lives, and the company or organization for which they work. When time is not used effectively, a backlog of work may occur which requires extra time to complete. For this reason, managers can be vulnerable to stress because of incessant deadlines. They may also be unable to improve their skills given the added pressure to accomplish tasks that have already been assigned.

The core of TM is based on two principles: the Pareto principle and Parkinson's law. The Pareto principle states that $80 \%$ of the effective results or rewards come from about $20 \%$ of the expended energy (or, in other words, the $80 / 20$ rule). However, Parkinson's law states that there is a tendency to spend extra time and effort on insignificant work rather than the more important aspects of a task. Defining what is most important can help people to achieve the targets more efficiently (1). It must also be noted that the concept of available time can change according to individuals, organizations, and societies (3).

Considering the target group of health organizations, when health is taken into consideration, people in this sector tend to be those who are much more sensitive to time. Within this scope, the concept of time has become more important in the field of healthcare management. Although healthcare managers and other managers might

Copyright (c) 2016, Iranian Red Crescent Medical Journal. This is an open-access article distributed under the terms of the Creative Commons Attribution-NonCommercial 4.0 International License (http://creativecommons.org/licenses/by-nc/4.0/) which permits copy and redistribute the material just in noncommercial usages, provided the original work is properly cited. 
have the same duration of time within which to complete their tasks, they spend different amounts of time on different tasks in order to achieve the best results for their respective profession. In the healthcare context in particular, it is necessary that time be used productively and managed effectively.

Effective TM can be determined by evaluating various factors such as general planning, prioritization, meeting management, substitution, and disorganization. The first factor, planning, requires forward-looking thinking in time. Planning must be realized by determining short-and long-term targets. Second, prioritization must involve the effective structuring of tasks in order of importance (4). As Margulis states, "Long hours are not a substitute of efficiency. Tasks not worth doing at all are not worth doing well" (5). Prioritization involves the effective deployment of resources among competing programs or people, and it is required at all levels of healthcare management (6). The TM matrix technique, which was developed by Steven Covey, can be used in prioritization. The matrix involves the categorization of work by considering the importance and the urgency in terms of the following combinations: important and urgent, important \& not urgent, not important and urgent, and not important and not urgent (1-7).

Unfortunately, most managers do not know how they spend their time. Thus, they need to learn how best to control the time that they have. By considering certain periods of time (for instance, two weeks) and observing how this period of time is spent, it is possible to evaluate the way in which time is spent on work. For instance, the particular types of work and activities that take up most of the time and those that waste time with unnecessary repetitions can be compared, and the balance between time spent on old versus new work can also be considered (8).

TM experts have identified various potential "time wasters," referring to interruptions, distractions, and other delays that insidiously reduce productive time (7). For instance, it is stated that $60 \%$ of the managers' reasons for wasting time are a result of interruptions caused by interactions with others (1). These interruptions can be decreased with effective planning and prioritization.

The third important TM factor for managers involves meetings. While they are necessary to lead the staff towards meeting certain aims, they can cause excessive time loss. An agenda must be prepared and distributed to the attendants before the meetings. Otherwise, most of the meeting is wasted in an attempt to determine the target.

Substitution means relying on somebody else and assigning him/her a duty through the allocation of administrative power. It requires a certain level of familiarity, respect, trust, and the available personnel who are interested in improving a particular situation. If the managers avoid substitution, in addition to having a short amount of time available for the more important work that they might have, they prevent the education and development of their subordinates (4-8), as well as more efficient productivity.

The last factor involves disorganization of the office. Irregularity and disorder cause time to be wasted. For instance, if an office is not organized, it can take hours to find a document on a table. Developing a system in advance for the efficient layout of the office can be useful.

The proverb "Never put off 'til tomorrow what you can do today" refers to the drawbacks of procrastination and ineffective TM. To put off work means causing a backlog and trying to finish work quickly and carelessly at a later period of time. Being organized and doing work on time is the core of success. Productivity and effectiveness at work require knowing when to say "no" and when to say "yes." As the scientist Kimelman once said, "If you always say 'no,' you end up being a jerk. But if you take on everything that comes your way, you will be so overloaded that you can't tend to your lab" (9). As a result of these considerations, it is clear that preventing time loss and using time effectively are bound up with the improvement of the TM behaviors of managers.

\section{Objectives}

In this study, the aim is to determine the TM behaviors of healthcare managers and the effects of demographic variables on these behaviors.

\section{Methods}

This cross-sectional and descriptive research was carried out on managers from five hospitals in Tekirdag, Turkey between March 25, 2013 and April 25, 2013. Two out of five of these hospitals were private, and other three were public. However, this research is not based on the difference between the hospitals because the workload and responsibilities for the managers in these hospitals are assumed to be same.

The data was collected through the survey method. In the questionnaire, a TM behavior scale developed by Yigit (Sahin) through validity and reliability analyses was used (10). The Cronbach's alpha coefficient of this scale was 0.888 and it was defined as having a high degree of reliability. While the declarations were being examined, "1" was graded as the lowest value and " 5 " was graded as the highest value. Also, it was assumed that the number of factors which may affect TM were reasonably limited to the eight factors considered in this study. Hospital managers 
were asked for their permission to complete the survey. The research population of 175 managers were targeted, and of the managers that were informed about the survey, 163 completed questionnaires. This sample of 163 managers was not restricted by any further sample determination method. This sample consisted of managers who work 40 hours per week. SPSS for Windows 15.0 package software was used to analyze the data. It was found in the Kolmogorov-Smirnov test that the scores do not show normal distribution $(\mathrm{P}<0.05)$. Therefore, the data was also tested with a Mann-Whitney $\mathrm{U}$ test and a Kruskal-wallis $\mathrm{H}$ test (post hoc Bonferroni-corrected Mann-Whitney U). The probability of error was determined as $\alpha=0.05$.

It should be noted that due to the small sample size in this study, the results cannot be generalized.

\section{Results}

4.1. Demographic Variables and the TM Behaviors of the Managers

It was found that $17.8 \%$ of the managers were health business managers, $53.4 \%$ were women, $78.5 \%$ were married, and $69.3 \%$ were state hospital personnel (Table 1). It was determined that $9.8 \%$ of the managers used their time very well, $52.8 \%$ used it well, and $28.8 \%$ used it poorly. It was found that $87.7 \%$ of the managers were most productive during the morning hours (between 8 - 11 a.m.).

Among managers, it was planning ( $3.72 \pm 0.59)$, meeting management $(3.84 \pm 0.53)$, determining priorities (3.96 \pm 0.53$)$, substitution $(3.78 \pm 0.62)$, table and file folder set up (3.66 \pm 0.59$)$, procrastination $(3.54 \pm 0.65)$, and answering unnecessary phone calls $(3.59 \pm 0.6)$ that were found to consume a lot of time; saying "no" to visitors $(3.38 \pm 0.58)$ was found to consume a moderate or average amount of time, and general TM behaviors $(3.65 \pm 0.40)$ were all found to be given a considerable amount of time.

\subsection{The Effect of Demographical Variables on the TM Behaviors of the Managers}

There was a statistically significant difference between the TM factors depending on the managers' titles, gender, marital status, education, experience as manager, use of time, and attendance of TM training $(\mathrm{P}<0.05)$. However, there was not a significant difference between the TM factors concerning age, management level, institutional experience and occupational experience $(\mathrm{P}>0.05)$. This is illustrated in Table 2.

A statistically significant difference was found between the groups in terms of planning $(\mathrm{P}=0.032)$, determining priorities $(\mathrm{P}=0.002)$, table or file folder set up $(\mathrm{P}=0.001)$, procrastination $(\mathrm{p}=0.001)$, and general factors $(\mathrm{P}=.010)$
Table 1. Demographic Variables

\begin{tabular}{|c|c|}
\hline Variables/Groups & No. (\%) \\
\hline \multicolumn{2}{|l|}{ Hospital } \\
\hline Public & $113(69.3)$ \\
\hline Private & $50(30.7)$ \\
\hline \multicolumn{2}{|l|}{ Administrative level } \\
\hline Senior (Hospital manager) & $6(3.6)$ \\
\hline $\begin{array}{l}\text { Mid-senior (Hospital asst. manager, nursing asst. } \\
\text { manager, deputy chief physician) }\end{array}$ & $23(14.1)$ \\
\hline Junior (Chief nurse, chief, unit supervisor, etc.) & $134(82.2)$ \\
\hline \multicolumn{2}{|l|}{ Title } \\
\hline Health Manager & $29(17.8)$ \\
\hline Physician & $47(28.8)$ \\
\hline Nurse & $66(40.5)$ \\
\hline Other & $21(12.9)$ \\
\hline \multicolumn{2}{|l|}{ Gender } \\
\hline Male & $76(46.6)$ \\
\hline Female & $87(53.4)$ \\
\hline \multicolumn{2}{|l|}{ Age } \\
\hline 40 and less & $87(53.4)$ \\
\hline 41 and more & $76(46.6)$ \\
\hline \multicolumn{2}{|l|}{ Marital status } \\
\hline Married & $128(78.5)$ \\
\hline Single & $35(21.5)$ \\
\hline \multicolumn{2}{|l|}{ Education } \\
\hline High school or equivalent & $21(12.9)$ \\
\hline Associate and Bachelor's degree & $81(49.7)$ \\
\hline Master's degree and Ph.D. & $61(37.4)$ \\
\hline \multicolumn{2}{|l|}{ Occupational experience, y } \\
\hline 5 and less & $22(13.5)$ \\
\hline $6-10$ & $22(13.5)$ \\
\hline $11-15$ & $26(16.0)$ \\
\hline $16-20$ & $38(23.3)$ \\
\hline 21 and more & $55(33.7)$ \\
\hline \multicolumn{2}{|l|}{ Organizational seniority, y } \\
\hline 5 and less & $75(46.0)$ \\
\hline $6-10$ & $30(18.4)$ \\
\hline 11 and more & $58(35.6)$ \\
\hline \multicolumn{2}{|l|}{ Time in management, $y$} \\
\hline Less than 1 & $27(16.6)$ \\
\hline $1-5$ & $66(40.5)$ \\
\hline 6 and more & $70(42.9)$ \\
\hline
\end{tabular}


according to the titles of the managers. The scores of determining priorities $(\mathrm{P}=0.0125)$ and procrastination $(\mathrm{P}=$ 0.0125) of the managers who were doctors were significantly lower than the scores of the nurses and members of other professions. Whereas table and file folder set up scores of the nurses were found to be significantly higher than the scores of healthcare business managers and doctors $(P=0.0125)$, their general factor scores were significantly higher than only the healthcare business managers $(\mathrm{P}=0.0125)$. Planning $(\mathrm{P}=0.006)$, determining priorities $(P=0.014)$, saying "no" to visitors $(P=0.047)$, table and file folder set up $(P=0.001)$, procrastination $(P=0.001)$ and general factors $(\mathrm{P}=.001)$ all scored significantly higher for women than for men. Whereas the single managers' scores of saying "no" to visitors were significantly higher than the scores of the married $(\mathrm{P}=0.024)$, no significant difference was found in terms of other factors.

Concerning the levels of education, a significant difference was found between the groups in terms of the scores of saying "no" to visitors $(\mathrm{P}=0.015)$, table and file folder set up $(P=0.003)$, and procrastination $(P=0.003)$. Whereas in saying "no" to visitors, the scores of the graduates of high schools and their equivalents were significantly lower than the scores of the graduates with an associate or bachelor's degree $(P=0.0167)$, the table and file folder set up scores of the graduates with associate and bachelor's degree were significantly higher than the scores of the experts and the graduates with a master's degree $(P=0.0167)$. The procrastination scores of the managers with a master's degree and expert managers were significantly lower than those of the high school graduates and the managers with a bachelor's or associate degree $(\mathrm{P}=0.0167)$.

According to the amount of time spent in management, a significant difference was determined among the groups in terms of substitution $(\mathrm{P}=0.038)$ and table and file folder set up $(P=0.026)$. In terms of substitution, the scores of healthcare managers who had worked between 1-5 years were significantly higher than those who had worked between 6 - 10 years $(P=0.0083)$; in terms of table and file folder set up, the scores of managers who had worked between 6 - 10 years were significantly higher than those who had worked between 1 - 5 years and over 11 years $(\mathrm{P}=0.0083)$. The general factor scores of healthcare managers who had worked less than 1 year were significantly lower than those who had worked between $6-10$ years $(\mathrm{P}=$ 0.0083).

According to the managers' own perceived use of time, apart from answering unnecessary phone calls $(P>0.05)$ and in terms of all other sub-factors, a significant difference between the groups was determined $(P<0.05)$. With respect to planning, the scores of the managers whose use of time was excellent were significantly higher than those whose use of time was good, average, or bad $(\mathrm{P}=0.0083)$; in terms of meeting management, the scores of managers whose use of time was excellent or good were significantly higher than those whose use of time was bad, and the scores of managers whose use of time was good were significantly higher than those whose use of time was average $(\mathrm{P}=0.0083)$. With respect to determining priorities, the scores of managers whose use of time was excellent, good, or average were significantly higher than those whose use of time was bad $(P=0.0083)$. In terms of substitution and saying "no" to visitors, the scores of managers whose use of time was good were significantly higher than those whose use of time was average or bad $(\mathrm{P}=0.0083)$. The scores of managers whose use of time was excellent or good were significantly higher than those whose use of time was average or bad $(\mathrm{P}=0.0083)$ in setting up tables and file folders. When it came to procrastination, managers whose use of time was excellent or good scored significantly higher than those whose use of time was average, and the scores of managers whose use of time was good were significantly higher than those whose use of time was average or bad (P $=0.0083$ ). When considering general TM factors, the scores of managers whose use of time was excellent, good, or average were significantly higher than those whose use of time was bad, and the scores of managers whose use of time was excellent or good were significantly higher than those whose use of time was average $(\mathrm{P}=0.0083)$.

\section{Discussion}

Time availability may cause positive or negative results on TM. For instance, in emergencies, if the available amount of time is short, then there could be lifethreatening results in the healthcare sector. Extra waiting times also indicate that service has failed in terms of meeting public health needs. In other cases, extra time may result in boredom and attention deficits $(11,12)$. However, a general problem is a shortage of time. This time shortage may put pressure on managers and impact their ability to make the best decisions (13).

One of the three most important areas in selfmanagement which leads managers to success is use of time (14). They must evaluate how effective their TM skills are and how their work is affected by their decisions. The reasons that contribute to wasting time, such as phone calls, not being able to say "no," lack of selfdiscipline, personal or professional crises, ineffective substitution, document loss, and socializing must not be ignored (15). Planning daily activities, putting priorities in order, building up trust by making long-term plans, and configuring available time can let creative ideas emerge and worries drift away (3-16). Thus, TM behaviors can lead 
to success and saving time. Therefore, time, which is one the most valuable resources of managers, needs to be managed effectively.

Whereas the fact that planning, meeting management, determining priorities, table and file folder set up, and answering unnecessary phone calls were scored highly in the study is positive, the fact that substitution and procrastination were also scored high is negative. It can be said that managers are generally well-organized and good planners, capable of prioritizing while working, keeping control of the required documents, and assuring that business phone calls are limited to a moderate length. However, they avoid substitution and put off work which could eventually lead to chaos. The fact that saying "no" to visitors had a moderate level of responses reveals the fact that the managers spend a lot of their time dealing with unnecessary visitors and performing the duties that others could possibly do. The fact that the general TM behavior scored high shows that the managers do make an effort to manage their time effectively and they realize this aim to a considerable extent. Still, they have some behaviors that need to be improved.

Measuring TM behaviors is important for ensuring high quality clinical care (17). Organizations and managers can deal with TM as an objective factor while evaluating the service that they provide. In their research, Reeleder et al. emphasize the importance of prioritization in health organizations from the perspective of managers (6). Similar to the research, TM behaviors in this study were significantly different according to educational status (10-19). However, contrary to the research, they do not show significant differences according to marital status (10-18), gender (18), or time spent in management (10), but they are significantly different according to age (10-18). In some studies similar to this research, it has been determined that the people who had TM training are more effective in their jobs and they are better at TM $(19,20)$. Also, gender is important in TM (21), since women have been determined to manage time better than men (22). Furthermore, it has also been shown that TM behaviors change according to work experience (19). Contrary to the research, however, other studies have shown that TM performance of the managers does not change between morning and afternoon hours (18).

What has been observed is that TM behaviors of the managers change according to demographic variables, and there are both similar and different results that can be compared with the results from this study. Generally, though, other studies have determined that TM has a great effect on work performance (23). Also, it increases work satisfaction and decreases work stress and procrastination (2-16). Moreover, it has been shown that TM behaviors are more effective in improving performance and work satis- faction in some countries compared to others (24). These studies all confirm the importance of TM behaviors.

How the managers use their times is also important. In their research, Kinney et al. also show that the use of time is very important (25). Managers must spare most of their time for administrative activities and establish a plan for meeting long-term targets; this provides them with continuity(26). Furthermore, managers must create an effective environment of communication by choosing either a horizontal, vertical, or standardized application of planned time, or by using them all together (27). Furthermore, they must also consider TM advice that that is specifically for managers. Some of this advice includes the following statements: Never waste your time. Be sure that you use your time economically. Just assign important, urgent personnel. Tell them the reason why they must complete the task. Give them enough time to finish it. Encourage them to complete their work on time so that they can achieve their goals. Organize meetings to have more productive personnel (15).

It must also be kept in mind that tacit knowledge is important in TM (28), and that TM behaviors may have different effects according to different positions of management. For these reasons, empathetic approaches must be adopted (29). Within this context, TM behaviors will help to develop more effective TM results.

It was determined that demographic variables affect the TM behaviors of managers. Generally it was also found that TM behaviors of the managers are relatively high; most of them use time well and they are most productive in the morning hours. However, managers can improve their TM abilities by determining their time-wasting behaviors and improving their TM skills (8). By emphasizing the importance of TM behaviors in healthcare service, managers need to be informed about the disadvantages of procrastination, avoiding substitution, and not saying "no" to visitors. They also need to be advised that they should do more planning, determine priorities in advance, and do the most important work when they are most productive; they should also work systematically on a regular basis, keep phone calls short, say "no" to others when necessary, allocate some of their duties to others, and avoid unnecessary meetings. Furthermore, by participating in TM training, their TM behaviors and skills can be improved and augmented by different TM behaviors. Within this context, individual TM behaviors will help to develop an environment with more effective TM.

As can be expected, this research is intended to help healthcare managers improve their TM behaviors, and to support the effective implementation of TM strategies in healthcare environments. 


\section{Acknowledgments}

The manuscript was discussed at the 4 th international health and hospital management congress.

\section{Footnote}

Authors' Contribution: Aygul Yanik: design, analysis and/or interpretation, literature review, writing and editing the manuscript; Meryem Ortlek: design, data collection and writing the manuscript.

\section{References}

1. Brunicardi FC, Hobson FL. Time management: A review for physicians. J Nat Med Assoc. 1996;88(9):581-7.

2. Roe RA. A review of the time management literature. Personnel Rev. 2007;36(2):256-76.

3. Darini M, Pazhouhesh H, Moshiri F. Relationship between Employee's Innovation (Creativity) and time management. Proc Soc Behav Sci. 2011;25:201-13. doi: 10.1016/j.sbspro.2011.10.541.

4. Adair J. Effective time management: How to save time and spend it wisely. Pan Macmillan; 2009.

5. Jackson VP. Time Management: A Realistic Approach. J Am College Radiol. 2009;6(6):434-6. doi:10.1016/j.jacr.2008.11.018.

6. Reeleder D, Goel V, Singer PA, Martin DK. Leadership and priority setting: The perspective of hospital CEOs. Health Policy. 2006;79(1):24-34. doi: 10.1016/j.healthpol.2005.11.009.

7. Gordon CE, Borkan SC. Recapturing time: a practical approach to time management for physicians. Postgraduate Medical Journal. 2014;90(1063):267-72. doi:10.1136/postgradmedj-2013-132012.

8. Arnold E, Pulich M. Improving Productivity Through More Effective Time Management. Health Care Manag. 2004;23(1):65-70. doi: 10.1097/00126450-200401000-00011.

9. Kiefer JC. Tips for success: Getting more done in less time. Dev Dynamics. 2011;240(6):1635-7. doi:10.1002/dvdy.22638.

10. Yigit E. Determination of the nurse managers' behaviors for time management. Istanbul: Marmara University; 2013.

11. Zhang Y, Goonetilleke RS, Plocher T, Max Liang SF. Time-related behaviour in multitasking situations. Int J Human Comput Stud. 2005;62(4):425-55. doi:10.1016/j.ijhcs.2005.01.002.

12. Bruni RA, Laupacis A, Levinson W, Martin DK. Public views on a wait time management initiative: a matter of communication. BMC Health Serv Res. 2010;10(1) doi: 10.1186/1472-6963-10-228.

13. Bluedorn AC, Jaussi KS. Leaders, followers, and time. Leadersh Q. 2008;19(6):654-68. doi:10.1016/j.leaqua.2008.09.006.

14. McConnell CR. Self-management. Health Care Manag. 2010;29(1):8393. doi: 10.1097/HCM.0b013e3181cd8c4d.
15. Zerihun TB, Krishna SM. A few techniques for time management. J Business Manag Soc Sci Res. 2012;1(3):32-7.

16. Kelly WE. No time to worry: the relationship between worry, time structure, and time management. Pers Individ Differ. 2003;35(5):111926. doi: 10.1016/s0191-8869(02)00322-7.

17. Braddock $\mathrm{CH}$, Snyder L. The doctor will see you shortly. J General Internal Med. 2005;20(11):1057-62. doi:10.1111/j.1525-1497.2005.00217.x.

18. Sarp N, Yarpuzlu A, Mostame F. Assessment of Time Management Attitudes Among Health Managers. Health Care Manag. 2005;24(3):22832. doi: 10.1097/00126450-200507000-00007.

19. Ebrahimi H, Hosseinzadeh R, Tefreshi M, Hosseinzadeh S. Time management behaviors of head nurses and staff nurses employed in Tehran Social Security Hospitals, Iran in 2011. Iranian J Nurs Midwifery Res. 2014;19(2):193.

20. Orpen C. The Effect of Time-Management Training on Employee Attitudes and Behavior: A Field Experiment. J Psychol. 1994;128(4):393-6. doi: 10.1080/00223980.1994.9712743.

21. Ozbilgin MF, Tsouroufli M, Smith M. Understanding the interplay of time, gender and professionalism in hospital medicine in the UK. Soc Sci Med. 2011;72(10):1588-94. doi:10.1016/j.socscimed.2011.03.030.

22. Kaya H, Kaya N, Pallos AO, Kucuk L. Assessing time-management skills in terms of age, gender, and anxiety levels: A study on nursing and midwifery students in Turkey. Nurs Educ Pract. 2012;12(5):284-8. doi: 10.1016/j.nepr.2012.06.002

23. Ahmad NL, Mohd. Yusuf AN, Mohamed Shobri ND, Wahab S. The Relationship between Time Management and Job Performance in Event Management. Proc Soc Behav Sci. 2012;65:937-41. doi: 10.1016/j.sbspro.2012.11.223.

24. Nonis SA, Teng JK, Ford CW. A cross-cultural investigation of time management practices and job outcomes. Int $J$ Intercultur Relat 2005;29(4):409-28. doi:10.1016/j.ijintrel.2005.05.002.

25. Kinney KG, Boyd SYN, Simpson DE. Guidelines for appropriate in-hospital emergency team time management: the Brooke Army Medical Center approach. Resuscitation. 2004;60(1):33-8. doi: 10.1016/s0300-9572(03)00259-4.

26. Pomey MP, Forest PG, Sanmartin C, DeCoster C, Clavel N, Warren E, et al. Toward systematic reviews to understand the determinants of wait time management success to help decision-makers and managers better manage wait times. Implement Sci. 2013;8(1) doi: 10.1186/1748 5908-8-61.

27. Mason K, Leek S. Communication practices in a business relationship: Creating, relating and adapting communication artifacts through time. Indust Market Manag. 2012;41(2):319-32. doi: 10.1016/j.indmarman.2012.01.010

28. Kleshinski O, Dunn TG, Kleshinski JF. A preliminary exploration of time management strategies used by physicians in the United States. Int J Med Educ. 2010;1:47-54. doi: 10.5116/ijme.4c23.117d.

29. Klitzman R. "Patient-time", "doctor-time", and "institutiontime": Perceptions and definitions of time among doctors who become patients. Patient Educ Counsel. 2007;66(2):147-55. doi: 10.1016/j.pec.2006.10.005. 


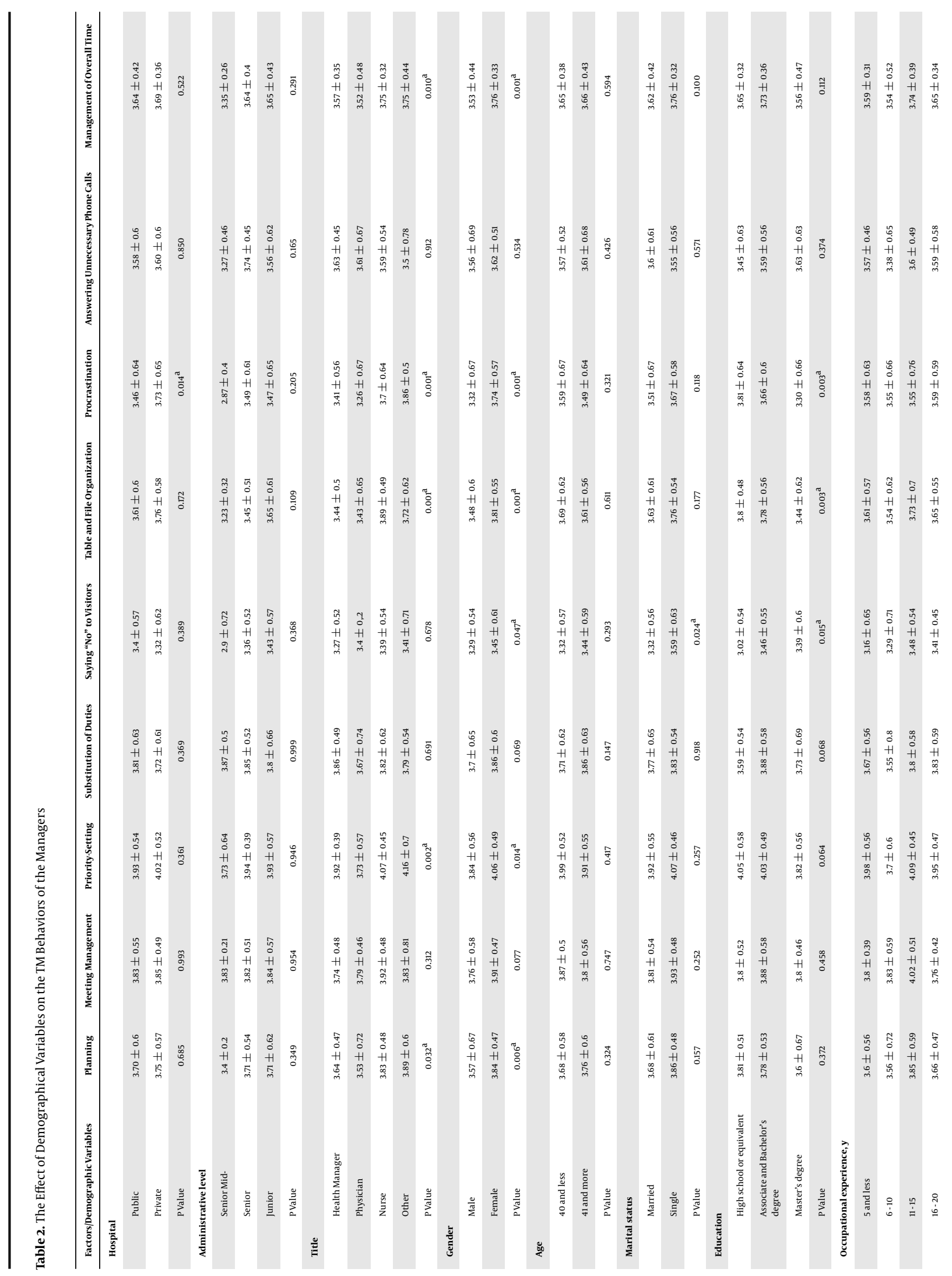




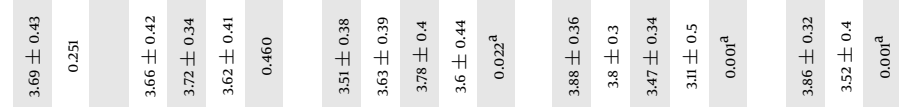

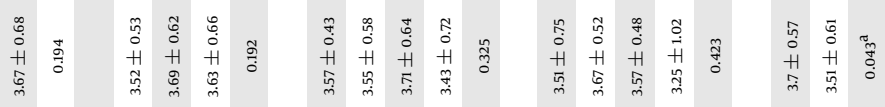

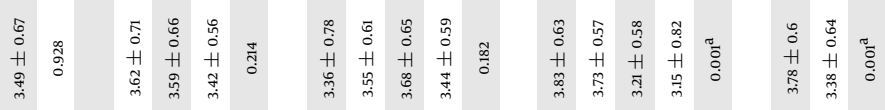

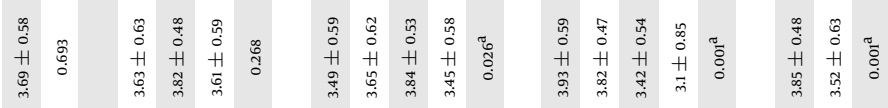

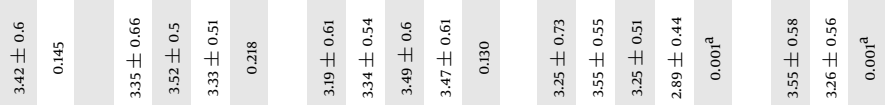

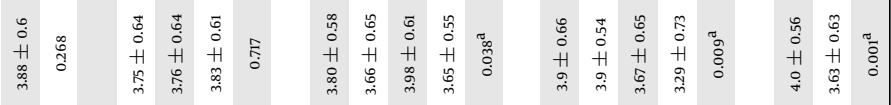

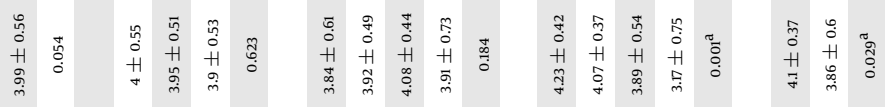

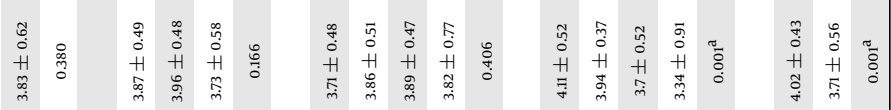

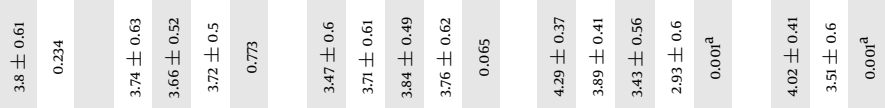

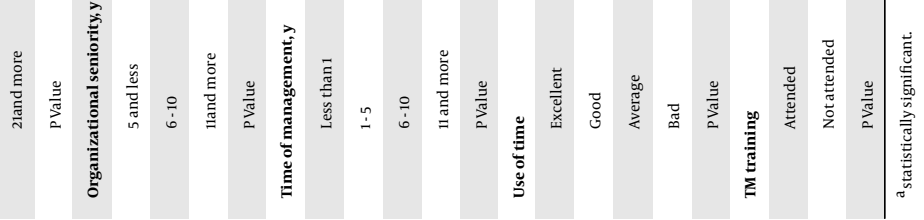

